\title{
O ESPAÇO ACADÊMICO DA PEDAGOGIA NO BRASIL: PERSPECTIVA HISTÓRICA ${ }^{1}$
}

\author{
Dermeval Saviani ${ }^{2}$ \\ FFCLRP - Universidade de São Paulo \\ Professor Emérito da UNICAMP
}

\begin{abstract}
Resumo: Este estudo parte da explicitação do significado da "Faculdade de Educação, Ciências e Letras", prevista no "Estatuto das Universidades Brasileiras" instituído em 1931, em correlação com a "Faculdade de Filosofia, Ciências e Letras" tal como proposta na criação da USP, em 1934, passa pelo breve ensaio de um modelo alternativo representado pela Universidade do Distrito Federal, fundada em 1935, e reconstitui a trajetória do Curso de Pedagogia desde sua criação, em 1939, até o momento presente. A conclusão do trabalho aponta para a constatação de que a excessiva preocupação do movimento dos educadores e dos estudiosos da questão com a regulamentação, isto é, com os aspectos organizacionais, tem dificultado o exame dos aspectos mais substantivos referentes ao próprio significado e conteúdo da pedagogia sobre cuja base cabe estruturar o curso correspondente. Daí que a continuidade da investigação deverá articular a abordagem histórica com a perspectiva teórica do problema em estudo.
\end{abstract}

Palavras-Chave: pedagogia; história da educação; educação brasileira.

\section{THE ACADEMIC SPACE OF PEDAGOGY IN BRAZIL: A HISTORIC PERSPECTIVE}

Abstract: This study starts from the explicitation of the meaning of "Faculdade de Educação, Ciências e Letras" (School of Education, Sciences, and Letters) in relation to "Faculdade de Filosofia, Ciências e Letras" (School of Philosophy, Sciences, and Letters) as proposed at the creation of the USP, covering the brief attempt of an alternative model represented by the Universidade do Distrito Federal (Federal District University) and reconstitutes the course of the Study of Pedagogy since its creation in 1939 to the current days. The conclusion of the work shows the verification that the excessive concern of the movement of the educators and of the scholars of the topic about the regulation, that is, about its organizational aspects, has hindered the examination of the more substantial aspects of the very meaning and contents of a Pedagogy whose foundation must structure the corresponding study. Thus the continuation of the investigation, beyond this work, should articulate the historical approach with the theoretical perspective of the problem in study.

Key-Words: pedagogy; history of education; brazilian education.

As tentativas de elevar os estudos de educação ao nível superior remontam à reforma da instrução pública paulista do início da República. A Lei n.88, de 1892, instituiu o Curso Superior da Escola Normal com dois anos de duração, tendo como finalidade a formação de professores para as escolas normais e ginásios (Reis Filho, 1995, p.162). Mas, em-

\footnotetext{
${ }^{1}$ Artigo recebido para publicação em 20/05/2004; aceito em 13/08/2004. ${ }^{2}$ Endereço para correspondência: Dermeval Saviani, Rua Visconde do Rio Claro, 338, Campinas, SP, Cep 13083-650, E-mail: dermevalsaviani@yahoo.com.br
}

bora essa legislação tenha permanecido até a reforma de 1920, o curso superior previsto jamais foi implantado.

Essa questão é retomada em 1931 quando, no Decreto 19.851/31 que baixou o Estatuto das Universidades Brasileiras, se prevê, entre as faculdades necessárias para se constituir uma universidade no Brasil, a de Educação, Ciências e Letras. É nesse momento, portanto, que se origina nosso estudo. Considerando-se que o conceito de academia, na acepção deste trabalho, se aplica por excelência às 


\section{Dermeval Saviani}

universidades, estamos pensando o enunciado "espaço acadêmico da pedagogia”" como o lugar ocupado pelos estudos de educação no âmbito do ensino superior e, mais especificamente, nas universidades. E o referido decreto, exatamente quando se propõe a regular o funcionamento das universidades estabelecendo as condições para que uma instituição de ensino superior se constitua como universidade, introduz a educação como uma dessas condições.

É certo que essa condição aparece, no decreto, apenas como uma possibilidade e não como uma exigência impositiva, uma vez que a "Faculdade de Educação, Ciências e Letras” figura, ao lado das tradicionais faculdades de Direito, Medicina e Engenharia, entre as quatro unidades dentre as quais pelo menos três são definidas como indispensáveis para constituir uma universidade. Assim, de fato, continuava possível a instituição de universidades com as três faculdades tradicionais sem se abrir o espaço acadêmico para os estudos educacionais. Mas o simples fato dessa nova faculdade figurar ao lado das três tradicionais com peso equivalente podendo somarse a elas ou, até mesmo, substituir uma delas na organização da universidade já representa um indicador da importância que se passou a dar aos estudos superiores de educação. E, efetivamente, como se procurará evidenciar, o espaço acadêmico dos estudos educacionais não deixou de se firmar, a partir daí, no âmbito das universidades.

\section{O significado da Faculdade de Educação, Ciênci- as e Letras}

O ministro Francisco Campos, responsável pela elaboração do Decreto relativo ao Estatuto das Universidades Brasileiras, em longa exposição de motivos esclarece as razões da introdução da Faculdade de Educação, Ciências e Letras no texto do Estatuto, como condição possível e não obrigatória, assim como na reorganização da Universidade do Rio de Janeiro, efetivada pelo Decreto n.19.852/31, definida pelo ministro como "modelo para as universidades e institutos equiparados” (Campos. Em Fávero, 2000, p.126). Considera ele que é essa Faculdade que permite à universidade transcender "os limites do interesse puramente profissional" imprimindo-lhe o caráter de universalidade (Campos. Em Fávero,
2000, p.127).

Trata-se, porém, de uma aspiração geral que resulta, na prática, não apenas relativizada, mas cujo sentido é, até mesmo, invertido. Entende o ministro que, em razão "do nosso estado de cultura e dos defeitos e vícios do nosso ensino”, a instalação dessa nova faculdade teria um "papel eminentemente utilitário e prático". Conseqüentemente, a nova faculdade não seria apenas um "órgão de alta cultura ou de ciência pura e desinteressada” mas deveria ser, "antes de tudo e eminentemente, um Instituto de Educação" cuja função precípua seria a formação dos professores, sobretudo os do ensino normal e secundário (Campos. Em Fávero, 2000, p.127).

Fica claro, portanto, na visão do ministro, o motivo pelo qual se optou pela denominação "Educação, Ciências e Letras” para a nova faculdade introduzida na organização do sistema universitário com a entrada em vigor do Estatuto das Universidades Brasileiras.

Entretanto, embora o Decreto n.19.852/31, que reorganizou a Universidade do Rio de Janeiro, tenha introduzido a Faculdade de Educação, Ciências e Letras em caráter obrigatório, esse dispositivo legal não se concretizou "por haver, da parte do Colégio Pedro II, interesse em que a nova faculdade fosse integrada ao colégio”. O ministro, porém, não reconhecendo "a competência ou capacidade" do Colégio Pedro II "para assumir tão alta responsabilidade”, adiou a solução do problema (Fávero, 2000, p.47). Portanto, a nova faculdade embora legalmente instituída, não chegou a ser instalada.

Ao ser criada a Universidade de São Paulo em 1934, definiu-se como espinha dorsal da nova instituição a Faculdade de Filosofia, Ciências e Letras que, na concepção de seus fundadores, assumia o caráter de alma mater da universidade. Cultivando todos os ramos do saber, promovendo o ensino de disciplinas comuns aos demais institutos universitários e colaborando na formação dos professores secundários e do próprio ensino superior, a Faculdade de Filosofia, Ciências e Letras se constituiria, ao mesmo tempo, no alicerce e na cúpula da universidade.

Assim concebida, a Faculdade de Filosofia, Ciências e Letras se destinava ao cultivo do saber desinteressado em que "a ciência pela ciência era a 
regra e o espírito de pesquisa e investigação seria o princípio norteador de todos os trabalhos” (Fávero, 2000, p.60). Distanciava-se claramente, portanto, do caráter "utilitário e pragmático" atribuído à Faculdade de Educação, Ciências e Letras. Com efeito, na estrutura da USP, o espaço da educação não se encontrava na Faculdade de Filosofia, Ciências e Letras, mas no Instituto de Educação, que se constituiu por incorporação da Escola de Professores do antigo Instituto "Caetano de Campos" (Decreto 6.283/34. Em: Fávero, 2000, p.211).

Portanto, o Instituto de Educação tinha um caráter de formação profissional (a formação de professores para as escolas normais e secundárias) do mesmo modo que os demais institutos ou faculdades. Portanto, seus alunos também deveriam passar pela Faculdade de Filosofia, Ciências e Letras já que "lá os estudantes estudariam as matérias fundamentais de todos os cursos (matemática, física, química, biologia, estatística, economia e outras), após o que se encaminhariam para as faculdades propriamente profissionais” (Cunha, 1986, p.270).

O papel atribuído à Faculdade de Filosofia, Ciências e Letras pelos fundadores da USP se ligava ao objetivo de formação de uma elite dirigente respaldada nos conhecimentos científicos. Mas a sua implantação esbarrou na resistência das faculdades profissionalizantes que não aceitavam a centralização das disciplinas básicas na nova faculdade. Assim, a partir de 1938 também ela veio a se tornar, como as demais, uma escola profissional com o objetivo de formar professores para o ensino médio. É nesse contexto que, pelo Decreto 9.269, de 1938, extinguiu-se o Instituto de Educação que foi absorvido pela Faculdade de Filosofia, Ciências e Letras como seção de Educação.

\section{Um modelo alternativo é ensaiado}

A conquista de um espaço acadêmico para a pedagogia se beneficiou do processo de organização do campo educacional que se desencadeou na década de 1920, impulsionado pelo movimento renovador. A organização do campo educacional implicava a profissionalização da atividade dos educadores. E a profissionalização, por sua vez, implicava uma formação específica, o que se iniciou com a criação de escolas normais para a formação de professores primários. Colocava-se, porém, a questão da formação dos professores das escolas normais e do ensino secundário em seu conjunto, o que acabou por pôr a exigência de se abrir espaço para os estudos pedagógicos em nível superior.

Por outro lado, o movimento renovador não apenas deu maior visibilidade às críticas dirigidas às escolas normais, mas se empenhou em oferecer um novo modelo que corrigisse as insuficiências e distorções do modelo então vigente.

Provavelmente onde as novas idéias assumiram uma formulação mais orgânica e conseqüente, encarnando-se numa experiência prática, foi na gestão de Anísio Teixeira como Diretor Geral de Instrução do então Distrito Federal. Na Exposição de Motivos do Decreto 3.810, de 19 de março de 1932, Anísio Teixeira deixa clara a intenção de erradicar aquilo que ele considerava como o "vício de constituição" das escolas normais que, "pretendendo ser, ao mesmo tempo, escolas de cultura geral e de cultura profissional, falhavam lamentavelmente nos dois objetivos” (Vidal, 2001, p.79-80). E em outro texto denominado "Como ajustar os 'cursos de matérias' na escola normal com os 'cursos de prática de ensino'”, indicava o caminho a seguir: "Se a 'escola normal' for realmente uma instituição de preparo profissional do mestre, todos os seus cursos deverão possuir o caráter específico que lhes determinará a profissão do magistério” (Vidal, 2001, p.80).

Guiando-se por essa concepção Anísio traçou o programa ideal que deveria ser implantado nas escolas normais, compreendendo:

“A) Cursos de fundamentos profissionais em que se devem incluir os que oferecem conhecimentos gerais e preliminares para a atividade educativa, como biologia educacional, sociologia educacional etc.; B) Cursos específicos de conteúdo profissional - em que se devem incluir todos os que fornecem o material e conteúdo propriamente ditos do tipo especial de ensino, a que se destina o estudante como os cursos de matérias de ensino, em geral, ou da matéria de ensino especializada; $\boldsymbol{C}$ ) Cursos de integração profissional - em que se incluem todos os cursos de técnica educativa 
116 Dermeval Saviani

ou de filosofia ou cultura geral educativa, que ministram os elementos científicos dos métodos, a sua prática e, ainda, a cultura geral relativa à profissão, como os cursos de psicologia educacional, de testes e medidas, de administração, de técnicas de ensino, de filosofia e história da educação e deobservação, participação e prática de ensino" (Vidal, 2001, p.8182).

Após essa citação Diana Vidal acrescenta:

"A constituição da Escola de Professores do Instituto de Educação eraexemplo prático de observância do modelo ideal. No primeiro ano geral do curso, estudavam-se: Biologia Educacional, Psicologia Educacional, Sociologia Educacional, História da Educação, Introdução ao Ensino - Princípios e Técnicas, Matérias de Ensino (Cálculo, Leitura e Linguagem, Literatura Infantil, Estudos Sociais, Ciências Naturais) e Prática de Ensino (observação, experimentação e participação)" (Vidal, 2001, p.82).

Com uma estrutura de apoio que envolvia Jardim de Infância, Escola Primária, Escola Secundária, que funcionavam como "campo de experimentação, demonstração e prática de ensino aos cursos da Escola de Professores”, um Instituto de Pesquisas Educacionais, Biblioteca Central de Educação, Bibliotecas escolares, Filmoteca, Museus Escolares e Radiodifusão, e tendo como diretor Lourenço Filho, a Escola Normal, agora transformada em Escola de Professores, se empenhou em pôr em prática o modelo ideal acima descrito. Em 1935, com a criação da Universidade do Distrito Federal, também por iniciativa de Anísio Teixeira, a Escola de Professores a ela foi incorporada com o nome de Escola de Educação.

A Universidade do Distrito Federal foi instituída pelo Decreto n. 5.513, de 04 de abril de 1935, tendo como um de seus fins, "prover a formação do magistério, em todos os seus graus". Entre seus órgãos constitutivos figuravam o Instituto de Educação e "instituições complementares para experimentação pedagógica, prática de ensino, pesquisa e difu- são cultural”. No texto do Decreto o Instituto de Educação é assim descrito:

"O Instituto de Educação que tem por fim prover formação do magistério e concorrer, como centro de documentação e pesquisa, para a formação de uma cultura pedagógica nacional, fica diretamente incorporado à Universidade pela sua atual Escola de Professores, que passa a denominar-se Escola de Educação, mantidos os objetivos estabelecidos pelo Decreto n. 3.810, de 19 de março de 1932 " (Fávero, 2000, p.235).

As instituições complementares eram as seguintes: a) a Biblioteca Central de Educação; b) a Escola-Rádio; c) a Escola Secundária do Instituto de Educação; d) a Escola Elementar do Instituto de Educação; e) o Jardim de Infância do Instituto de Educação; f) uma escola secundária técnica; g) uma escola elementar experimental; h) uma escola maternal experimental; i) laboratórios e clínicas dos hospitais do Distrito Federal (Fávero, 2000, p.235-236). Com exceção da alínea i, todas essas instituições estavam diretamente referidas aos estudos educacionais, configurando aquilo que estou chamando de "espaço acadêmico da pedagogia”. Eis porque a Universidade do Distrito Federal foi considerada como "universidade de educação” (Mendonça, 2002, p.35).

Mas, ainda em 1935, Anísio Teixeira, "perseguido pelo governo Vargas, acusado de professar idéias comunistas, deixava a Instrução Pública carioca” (Vidal, 2001, p.20). Nesse clima desfavorável "a recém-criada universidade sofreu grave revés” (Fávero, 2000, p.72), resultando, na expressão de Maria de Lourdes Fávero, na “utopia vetada”. O veto se consumou com o Decreto n. 1063 de 20 de janeiro de 1939 que extinguiu essa universidade incorporando seus cursos à Universidade do Brasil que havia sido organizada pela Lei n. 452, de 5 de julho de 1937 por iniciativa do ministro da educação, Gustavo Capanema, um dos principais opositores de Anísio Teixeira e de sua "universidade de educação".

Na verdade a Universidade do Brasil resultou da reorganização da Universidade do Rio de Janeiro vindo, depois, a se configurar como a atual Universidade Federal do Rio de Janeiro. A estrutura da Uni- 
versidade do Brasil, pensada como modelo padrão para todo o país, previa a existência de quinze faculdades, todas adjetivadas de "nacional". As duas primeiras da lista eram a Faculdade Nacional de Filosofia, Ciências e Letras e a Faculdade Nacional de Educação. Mas, a partir de 1939, a Faculdade de Filosofia, Ciências e Letras da Universidade do Brasil, assim como aquela da USP, acentuou sua característica profissionalizante prevalecendo, portanto, o espírito "utilitário e pragmático" que Francisco Campos atribuíra à Faculdade de Educação, Ciências e Letras. Quanto à Faculdade Nacional de Educação, embora prevista em lei, não chegou a ser implantada.

\section{$O$ curso de pedagogia}

Como modelo padrão, a Universidade do Brasil determinou a organização do ensino superior no país durante todo o período que vai de 1940 a 1968, quando é aprovada a Lei 5.540/68, conhecida como lei da reforma universitária. A concepção que orientou a estrutura dessa universidade se contrapõe tanto à idéia inicial que presidiu à proposta de criação da Faculdade de Filosofia, Ciências e Letras da USP, quanto, principalmente, à Universidade do Distrito Federal. Enquanto nesta a formação profissional é ancorada no desenvolvimento de estudos e pesquisas e na observação e exercício prático das escolaslaboratório, naquela separa-se o profissional do cientista, deslocando-se o eixo das atividades universitárias para a formação profissional.

Compreende-se, assim, a razão de uma medida que, à primeira vista pareceria surpreendente, a saber, o teor do parágrafo único do artigo primeiro do Decreto que extinguiu a Universidade do Distrito Federal, incorporando-a à Universidade do Brasil. Eis, para maior clareza, a transcrição desse dispositivo do Decreto 1.063, de 20 de janeiro de 1939:

"Art. $1^{\circ}$ - Ficam incorporadas à Universidade do Brasil as instituições educativas e culturais que compõem a Universidade do Distrito Federal. Parágrafo único. Fica excluído das instituições de que trata este artigo o Instituto de Educação, com suas escolas secundária, primária e pré-primária” (Mendonça, 2002, p.114).
De fato, à primeira vista soa estranho esse parágrafo único. Com efeito, se o “caput” do artigo determina a incorporação das instituições educativas e culturais, como excluir exatamente os órgãos tipicamente educativos que constituíam o aspecto mais saliente, inovador e de maior envergadura da instituição que estava sendo incorporada? Mas essa estranheza se desvanece quando constata-se que, conforme explicitado pelo ministro Capanema, a Faculdade Nacional de Filosofia foi definida como "o estabelecimento federal padrão do ensino destinado à preparação do magistério secundário” (Mendonça, 2002, p.156), desempenhando um papel orientador e disciplinador da cultura do país. Como, nessa visão, o preparo de professores assumia o caráter de simples formação profissional, desvinculada do desenvolvimento de pesquisa, resultavam desnecessários aqueles órgãos cuja presença na universidade se justificava exatamente em função do objetivo de imprimir caráter científico ao processo de formação dos professores.

Pelo Decreto n. 1.190, de abril de 1939, a Faculdade Nacional de Filosofia foi estruturada em quatro seções: Filosofia, Ciências, Letras e Pedagogia acrescentando, ainda, a de Didática, considerada como "seção especial". Enquanto as seções de Filosofia, Ciências e Letras albergavam, cada uma, diferentes cursos, a de Pedagogia, assim como a seção especial de Didática, era constituída de apenas um curso cujo nome era idêntico ao da seção. Está aí a origem do Curso de Pedagogia.

Todos os cursos da Faculdade Nacional de Filosofia e, dado o seu caráter de modelo padrão, também das demais faculdades de filosofia, ciências e letras instaladas no país, se organizaram em duas modalidades: o bacharelado, com a duração de três anos, e a licenciatura. O curso de pedagogia foi definido como um curso de bacharelado ao lado de todos os outros cursos das demais seções da faculdade. O diploma de licenciado seria obtido por meio do curso de didática, com a duração de uma ano, acrescentado ao bacharelado. Está aí a origem do famoso esquema conhecido como " $3+1$ ".

Foram definidos, para todos os cursos, os respectivos currículos plenos. Para o Curso de Pedagogia foi previsto o seguinte currículo:

$1^{\circ}$ ano: Complementos de matemática; Histó- 


\section{Dermeval Saviani}

ria da filosofia; Sociologia; Fundamentos biológicos da educação; Psicologia educacional.

$2^{\circ}$ ano: Psicologia educacional; Estatística educacional; História da educação; Fundamentos sociológicos da educação; Administração escolar.

$3^{\circ}$ ano: Psicologia educacional; História da educação; Administração escolar; Educação comparada; Filosofia da educação.

Vê-se, pelo quadro acima, que psicologia educacional se destaca, pois é a única disciplina que figura em todas as séries. Em seguida posicionam-se história da educação e administração escolar, figurando em duas séries. Às demais disciplinas reservou-se apenas um ano de estudo.

O Curso de Didática, com duração de um ano, se compunha das seguintes disciplinas: Didática geral; Didática especial; Psicologia educacional; Fundamentos biológicos da educação; Fundamentos sociológicos da educação; Administração escolar. Assim, no caso do bacharel em pedagogia, para obter o título de licenciado, bastava cursar Didática geral e Didática especial, uma vez que as demais já faziam parte de seu currículo de bacharelado.

Pelos nomes das disciplinas nota-se, na organização formal, uma certa influência do ideário da Escola Nova. No entanto, como já se indicou ao se mostrar as diferenças entre os projetos da Universidade do Distrito Federal e da Universidade do Brasil, essa organização distancia-se do espírito que impregnava aquele ideário.

Ao instituir um currículo pleno fechado para o curso de pedagogia, em homologia com os cursos das áreas de filosofia, ciências e letras e não os vinculando aos processos de investigação sobre os temas e problemas da educação, o modelo implantado com o Decreto l.190, em lugar de abrir caminho para o desenvolvimento de estudos e pesquisas educacionais, acabou por enclausurar-se numa solução que se supôs universalmente válida, agravando progressivamente os problemas que se recusou a enfrentar. Com efeito, supondo que o perfil profissional do pedagogo já estaria definido, concebeu um currículo que formaria o bacharel em pedagogia entendido como o técnico em educação que, ao cursar didática geral e especial, se licenciaria como professor. Mas, quais seriam as funções técnicas próprias do pedagogo? Em que medida o currículo proposto para o bacharelado daria conta de formar esse técnico? E o licenciado em pedagogia poderia lecionar que matérias? Por suposto, as matérias constantes de seu currículo de bacharelado, como ocorria com os cursos das seções de filosofia, ciências e letras. No entanto, se no caso das demais seções as disciplinas cursadas figuravam no currículo das escolas secundárias, no caso da pedagogia a Lei Orgânica do Ensino Normal dispôs um currículo em que predominavam as matérias de cultura geral sobre as de formação profissional, e, além disso, essa mesma Lei determinava que, para lecionar no curso normal, "era suficiente, em regra, o diploma de ensino superior” (Silva, 2003, p.14).

Essa estrutura prevaleceu até 1961 quando foi aprovada a Lei n. 4.024, que se constituiu na primeira Lei de Diretrizes e Bases da Educação Nacional. Mas, paralelamente, o campo da educação foi se desenvolvendo. A criação, em 1938, do Instituto Nacional de Estudos Pedagógicos, o INEP, hoje Instituto de Estudos e Pesquisas Educacionais, a fundação da CAPES, Campanha de Aperfeiçoamento de Pessoal de Nível Superior, em 1951, e do Centro Brasileiro de Pesquisas Educacionais, em 1955, articulando os Centros Regionais de Pesquisas Educacionais (Xavier, 1999), são espaços que mantiveram oxigenado o campo educacional, tendo reflexos positivos no espaço acadêmico da pedagogia.

Uma nova regulamentação do Curso de Pedagogia decorreu do Parecer 251, elaborado por Valnir Chagas e aprovado pelo Conselho Federal de Educação em 1962.

A duração do curso foi definida em quatro anos, englobando o bacharelado e a licenciatura correspondendo, portanto, à duração anterior. A diferença fica por conta de uma certa flexibilidade, uma vez que as disciplinas de licenciatura poderiam ser cursadas concomitantemente com o bacharelado, não sendo necessário esperar o quarto ano. Com essa nova regulamentação deixava de vigorar, ao menos formalmente, o esquema " $3+1$ ".

No que se refere ao currículo foi mantido o caráter generalista, isto é, não foram, ainda, introduzidas as habilitações técnicas. O rol de disciplinas sofreu algumas alterações não, porém, em aspectos substantivos. Diferentemente da regulamentação anterior, não se fechou a grade curricular com a distribuição das disciplinas pelas quatro séries do 
curso. Essa tarefa foi deixada para as instituições.

O currículo da Licenciatura se compunha das seguintes matérias: Psicologia da educação: adolescência e aprendizagem; Elementos de administração escolar; Didática; Prática de ensino. Considerandose a revogação do esquema " $3+1$ ", a prática que se generalizou foi a de cursar Psicologia educacional, Didática e Elementos de administração escolar na segunda e terceira séries do curso, deixando-se Prática de ensino para a quarta série. Quanto ao curso de pedagogia, como já constavam de seu currículo Psicologia educacional e Administração escolar, para obter o título de licenciado bastava aos alunos cursar Didática e Prática de ensino.

Conforme o entendimento de Carmen da Silva, os legisladores regulamentaram o curso de pedagogia começando por onde deveriam terminar: "fixaram o currículo mínimo visando à formação de um profissional ao qual se referem vagamente e sem considerar a existência ou não de um campo de trabalho que o demandasse” (Silva, 2003, p.17).

Mas o campo educacional continuou se movendo. A década de 1960 foi uma época de intensa experimentação educativa. Além dos colégios de aplicação que se consolidaram nesse período (Warde. Em Garcia, 1980, p.101-131), surgiram os ginásios vocacionais (Ribeiro. Em Garcia, 1980, p.132-149), deu-se grande impulso à renovação do ensino de matemática (Montejunas. Em Garcia, 1980, p.150-163) e de ciências (Krasilchik. Em Garcia, 1980, p.164180), colocando em ebulição o espaço acadêmico da pedagogia. Essa década, contudo, assinala também o esgotamento do modelo renovador, evidenciado pelo encerramento, no final dos anos 60, das experiências mencionadas e pelo fechamento do Centro Brasileiro de Pesquisas Educacionais e dos Centros Regionais a ele ligados.

A entrada em vigor da lei da reforma universitária no final de 1968, ensejou uma nova regulamentação do Curso de Pedagogia, levada a efeito pelo Parecer 252/69, também de autoria de Valnir Chagas. Ele situa o tema referindo-se aos antecedentes da questão, esclarece as razões das opções adotadas e apresenta, em anexo, o anteprojeto de Resolução, cujo artigo primeiro ficou assim redigido:
"Art. $1^{\circ}$ - A formação de professores para o ensino normal e de especialistas para as atividades de orientação, administração, supervisão e inspeção, no âmbito de escolas e sistemas escolares, será feita no curso de graduação em Pedagogia, de que resultará o grau de licenciado com modalidades diversas de habilitação.” (BRASIL, CFE, 1969, p.113).

Quanto ao currículo a parte comum permaneceu com a mesma composição definida no Parecer 251/62, apenas a ela se acrescentando a matéria Didática. As habilitações previstas e respectivas matérias específicas foram as seguintes:

1. Orientação Educacional: Estrutura e Funcionamento do Ensino de $1^{\circ} \mathrm{Grau}$; Estrutura e Funcionamento do Ensino de $2^{\circ}$ Grau; Princípios e Métodos de Orientação Educacional; Orientação Vocacional; Medidas Educacionais.

2. Administração Escolar, para exercício nas escolas de $1^{\circ}$ e $2^{\circ}$ graus: Estrutura e Funcionamento do Ensino de $1^{\circ} \mathrm{Grau}$; Estrutura e Funcionamento do Ensino de $2^{\circ} \mathrm{Grau}$; Princípios e Métodos de Administração Escolar; Estatística Aplicada à Educação.

3. Supervisão Escolar, para exercício nas escolas de $1^{\circ}$ e $2^{\circ}$ graus: Estrutura e Funcionamento do Ensino de $1^{\circ}$ Grau; Estrutura e Funcionamento do Ensino de $2^{\circ} \mathrm{Grau}$; Princípios e Métodos de Supervisão Escolar; Currículos e Programas.

4. Inspeção Escolar, para exercício nas escolas de $1^{\circ}$ e $2^{\circ}$ graus: Estrutura e Funcionamento do Ensino de $1^{\circ} \mathrm{Grau}$; Estrutura e Funcionamento do Ensino de $2^{\circ} \mathrm{Grau}$; Princípios e Métodos de Inspeção Escolar; Legislação do Ensino.

5. Ensino das disciplinas e atividades práticas dos cursos normais: Estrutura e Funcionamento do Ensino de $1^{\circ} \mathrm{Grau}$; Metodologia do Ensino de $1^{\circ} \mathrm{Grau}$; Prática de Ensino na Escola de $1^{\circ} \mathrm{Grau}$ (estágio).

6. Administração Escolar, para exercício na escola de $1^{\circ}$ grau: Estrutura e Funcionamento do Ensino de $1^{\circ} \mathrm{Grau}$; Administração da Escola de $1^{\circ}$ Grau; Estatística Aplicada à Educação.

7. Supervisão Escolar, para exercício na escola de $1^{\circ}$ grau: Estrutura e Funcionamento do Ensino de $1^{\circ} \mathrm{Grau}$; Supervisão da Escola de $1^{\circ} \mathrm{Grau}$; Currículos e Programas. 


\section{Dermeval Saviani}

8. Inspeção Escolar, para exercício na escola de $1^{\circ}$ grau: Estrutura e Funcionamento do Ensino de $1^{\circ} \mathrm{Grau}$; Inspeção da Escola de $1^{\circ} \mathrm{Grau}$; Legislação do Ensino.

Quanto à duração do curso, deve-se observar que a reforma do ensino superior decorrente da Lei 5.540/68 e do Decreto-Lei 464, de 11 de fevereiro de 1969 eliminou o regime seriado introduzindo a matrícula por disciplina e o regime de créditos, o que foi implementado na forma de disciplinas semestrais, além de distinguir entre cursos de curta duração e de longa duração. Assim, o artigo quarto da Resolução estabeleceu que as habilitações numeradas de 1 a 5 teriam a duração mínima de duas mil e duzentas horas, devendo ser ministradas no mínimo em três e no máximo em sete anos letivos. Trata-se das habilitações que abrangem atividades nas escolas de primeiro e de segundo graus que, por esse motivo, seriam desenvolvidas em cursos de longa duração. Já no caso das habilitações numeradas de 6 a 8 , que se dirigem apenas às escolas de $1^{\circ}$ grau, estipulou-se a duração de mil e cem horas de atividades a serem ministradas no mínimo em um ano e meio e no máximo em quatro anos letivos configurando-se, portanto, como cursos de curta duração.

$\mathrm{O}$ artigo quinto abre a possibilidade de se organizar "habilitações específicas no Curso de Pedagogia, para o exercício de funções técnicas ou de assessoria” (p.115) tomando-se como objeto: a) as matérias da parte comum, exceto Sociologia Geral; b) as seguintes matérias da parte diversificada: Estrutura e Funcionamento do Ensino de $1^{\circ}$ Grau, Estrutura e Funcionamento do Ensino de $2^{\circ}$ Grau, Estrutura e Funcionamento do Ensino Superior, Estatística Aplicada à Educação, Legislação do Ensino, Medidas Educacionais, Currículos e Programas; c) "outras matérias e atividades pedagógicas incluídas nos planos das instituições de ensino superior”. Em relação a este último item a Resolução não faz nenhuma especificação, mas o Parecer lista, à guisa de exemplo, as seguintes matérias: Economia da Educação; Antropologia Pedagógica; Educação Comparada; Técnicas Audiovisuais de Educação; Rádio e Televisão Educativa; Ensino Programado; Educação de Adultos; Educação de Excepcionais; Clínica de Leitura; Clínica da Voz e da Fala; Higiene Escolar; Métodos e Técnicas de Pesquisa Pedagógica; etc.
O caput do artigo sexto determina a obrigatoriedade de realização de estágio supervisionado correspondente à prática das várias habilitações atingindo pelo menos 5\% da duração do curso, em cada caso. E o parágrafo único desse artigo exige, além do estágio, experiência de magistério para as habilitações em Orientação Educacional, Administração Escolar e Supervisão Escolar, não especificando o tempo de duração nem o momento em que essa experiência deveria ocorrer. Mas, pelo Parecer n.867/ 72, de 11 de agosto de 1972, Valnir Chagas corrige essa lacuna determinando a exigência de experiência de magistério "anterior ao ingresso no curso ou à obtenção do diploma, com duração não inferior a um ano letivo, no caso de Orientação Educacional, e a um semestre letivo nos demais casos" (BRASIL CFE, 1972, p.340).

Essa regulamentação, não obstante algumas tentativas de modificação, permaneceu em vigor até a aprovação da nova LDB em 20 de dezembro de 1996. Seu aspecto mais característico foi a introdução das habilitações visando formar "especialistas" em orientação educacional, administração escolar, supervisão escolar e inspeção escolar, além do professor para o ensino normal. Por esse caminho se pretendeu superar o caráter generalista do curso procurando privilegiar a formação de técnicos com funções supostamente bem especificadas no âmbito das escolas e sistemas de ensino que configurariam um mercado de trabalho também supostamente já bem constituído demandando, em conseqüência, os profissionais com uma formação específica que seria suprida pelo curso de pedagogia então reestruturado exatamente para atender a essa demanda.

Entretanto, a dupla suposição se revelou inconsistente. Nem as funções correspondentes aos mencionados “especialistas” estavam bem caracterizadas, nem se poderia dar como constituído um mercado de trabalho demandando aqueles profissionais. E também não se logrou superar o caráter generalista. $\mathrm{Na}$ verdade, se pretendeu continuar formando o generalista, pela parte comum do currículo e, pela parte diversificada, formar também o especialista. E ambas as coisas num mesmo curso de graduação e, mais grave ainda, admitida a possibilidade de se fazer isso em cursos de curta duração. Poder-se-ia pois, "mutatis mutandis", aplicar a essa regulamentação a 
mesma crítica que Anísio Teixeira havia dirigido às escolas normais da década de 1930: pretendendo ser, ao mesmo tempo, escolas de cultura geral e de cultura profissional, falhavam lamentavelmente nos dois objetivos.

Ao que parece o problema do encaminhamento que se deu à questão do curso de pedagogia reside numa concepção que subordina a educação à lógica de mercado. Assim, a formação ministrada nas escolas deveria servir à produtividade social, ajustandose às demandas de mão-de-obra que, por sua vez, são determinadas pelas leis que regem uma sociedade de mercado como esta em que se vive. Nessas circunstâncias, a questão educativa é reduzida dominantemente à sua dimensão técnica, afastando-se o seu caráter de arte e secundarizando, também, as exigências de embasamento científico. Daí a pretensão de formar os especialistas em educação por meio de algumas poucas regras compendiadas externamente e transmitidas mecanicamente, articuladas com o treinamento para a sua aplicação nas escolas. Eis porque se considerou como suficientes as matérias "estrutura e funcionamento do ensino" e "princípios e métodos", seguidas de uma outra de algum modo relacionada com a "especialidade" em referência: "legislação do ensino" para inspeção, "estatística” para administração, “currículos e programas” para supervisão e "orientação vocacional" e "medidas educacionais”, para orientação. Supõe-se, portanto, que a escola já está devidamente organizada e o ensino funcionando dentro de parâmetros adequados cabendo ao especialista inserir-se nela para garantir-lhe a eficiência por meio de uma racionalidade técnica que maximize sua produtividade. Trata-se, em suma, daquilo que passei a denominar de "concepção produtivista de educação" que, impulsionada pela "teoria do capital humano" formulada nos anos 50 do século XX, se tornou dominante em nosso país a partir do final da década de 1960 permanecendo hegemônica até os dias de hoje.

\section{Estudos superiores de educação}

Aprovada a Lei n. 5.692/71, Valnir Chagas se dedicou à tarefa de regular todo o sistema de ensino de acordo com a nova legislação. Elaborou e fez aprovar no CFE um conjunto de oito Indicações que co- brem praticamente todo o espectro da formação de professores, desde as licenciaturas da área de educação geral abrangendo os cursos de Ciências (Matemática, Física, Química, Biologia), de Estudos Sociais (Geografia, História, Organização Social e Política do Brasil, Educação moral e Cívica), Letras (Língua Portuguesa, Língua Estrangeira Moderna, Língua Clássica, com os necessários estudos literários), Educação Artística (Música, Artes Plásticas, Desenho, Artes Cênicas) e Educação Física (Ginástica e Atletismo, Técnica Desportiva, Recreação), passando pela formação pedagógica das licenciaturas, pelo preparo de especialistas em educação até a formação de professores para educação especial (Chagas, 1976).

Esse conjunto de medidas teria o significado de substituir o "curso de pedagogia", que sugeria uma visão restrita, pelos “estudos superiores de educação”, categoria bem mais ampla e pretensamente completa.

Entre as medidas propostas figura a Indicação 70 que previa "o preparo de especialistas em Educação e de professores para o ensino pedagógico de $2^{\circ}$ grau, assim como do pedagogo em geral” num curso organizado na forma de "habilitações acrescentadas a cursos de licenciatura” (Chagas, 1976, p.133).

A novidade dessa proposta reside, conforme o slogan lançado pelo autor ("formar o especialista no professor”), no fato de que a formação preconizada pressupõe destinatários já licenciados, o que a situaria no âmbito da pós-graduação "lato sensu". Entretanto, o autor, talvez para poder abarcar também a "solução transitória” dos que têm apenas formação de $2^{\circ}$ grau, a situa na própria graduação, como habilitações que se acrescentam a uma licenciatura anterior.

Quanto ao conteúdo, não é muito diferente do que foi disposto no Parecer 252/69. Apenas foram feitos os ajustes necessários à nova situação. Assim, nas disciplinas da base comum, não consta Psicologia Educacional porque ela já teria sido cursada na licenciatura anterior. As habilitações sofrem um novo arranjo, seja pela supressão da "Inspeção" que foi absorvida no interior da "Administração", seja pelo conteúdo interno a cada uma delas, seja, ainda, porque a proposta admite três possibilidades: a) a organização de três habilitações correspondentes a Administração, Supervisão e Orientação (esquema triplo); b) a organização de duas habilitações, uma de- 


\section{Dermeval Saviani}

las sendo chamada de "dupla” porque abarca Supervisão e Orientação, ao lado da Administração (esquema duplo); c) a reunião das três funções em uma habilitação polivalente em Educação (esquema único). Em qualquer das hipóteses exige-se experiência profissional prévia no magistério com a duração mínima de dois anos.

Na Indicação aparece também uma referência ao "pedagogo em geral”, cujo nível natural de cultivo seria o da pós-graduação.

Fica claro, portanto, que, na concepção do autor tenderia a não haver mesmo espaço para o Curso de Pedagogia.

A Indicação referida chegou a ser homologada mas, diante das dúvidas suscitadas e das pressões contrárias, sua entrada em vigor foi sustada, prevalecendo, até a aprovação da nova LDB, a estrutura prevista no Parecer 252/69. Segundo Iria Brzezinski, o "pacote" de Indicações estimulou o movimento dos educadores que "era contra as possíveis mudanças que, em sua essência, propugnavam a extinção do curso de pedagogia e descaracterizavam ainda mais a profissão de pedagogo, que paulatinamente seria extinta” (Brzezinski, 2002, p.82).

O movimento dos educadores em torno da formação dos profissionais da educação começou a se articular no final da década de 1970 e se materializou com a criação, em 1980, do "Comitê Pró Participação na Reformulação dos Cursos de Pedagogia e Licenciatura”. O Comitê se organizou na forma de comissões regionais, transformou-se, em 1983, em Comissão Nacional pela Reformulação dos Cursos de Formação de Educadores (CONARCFE) que, por sua vez, em 1990, se constituiu na Associação Nacional pela Formação dos Profissionais da Educação (ANFOPE) que continua em atividade.

Essa mobilização foi importante para manter vivo o debate, articular e socializar as experiências que se realizaram em diferentes instituições, manter a vigilância sobre as medidas de política educacional, explicitar as aspirações, reivindicações e perplexidades e buscar algum grau de consenso na direção da solução do problema. Em termos concretos emergiram do movimento duas idéias-força. A primeira se traduz no entendimento de que a docência é o eixo sobre o qual se apóia a formação do educador. A partir dessa idéia prevaleceu entre as instituições a ten- dência a organizar o curso de pedagogia em torno da formação de professores, seja para a habilitação magistério, em nível de $2^{\circ}$ grau, seja, principalmente para atuar nas séries iniciais do ensino fundamental. A segunda idéia se expressa na "base comum nacional”. Em vários dos eventos realizados essa idéia foi retomada sendo explicitada mais pela negação do que pela afirmação. Foi se fixando o entendimento que "base comum nacional" não coincide com a parte comum do currículo nem com a idéia de currículo mínimo. Seria, antes, um princípio que deveria inspirar e orientar a organização dos cursos de formação de educadores em todo o país. Seu conteúdo não poderia ser fixado por um intelectual de destaque, por um órgão de governo e nem mesmo por decisão de uma eventual assembléia de educadores mas deveria fluir das análises, dos debates e das experiências que fossem encetadas possibilitando, progressivamente, chegar a um consenso em torno dos elementos fundamentais da formação do educador consciente e crítico, capaz de contribuir na transformação da sociedade brasileira.

Nesse período, de 1970 em diante, já não se assiste à busca de bases científicas à prática pedagógica como ocorreu no primeiro momento com o INEP, CBPE e CRPEs e, no segundo momento, com as escolas de aplicação, classes experimentais e ginásios vocacionais. Em contrapartida, instalam-se os Programas de Pós-Graduação em Educação, ampliando significativamente o espaço acadêmico da pedagogia. Isto se deu pela aproximação com as áreas afins das ciências humanas, consolidando-se o lugar da educação nesse âmbito na medida, porém, em que se afastava, por assim dizer, da pedagogia enquanto teoria e prática da educação ou, dizendo de outro modo, enquanto ciência da e para a prática educativa. Assim, enquanto os Programas de Pós-Graduação em Educação demonstravam toda sua pujança, o Curso de Pedagogia definhava e se debatia em uma crise de tal profundidade que projeta a impressão de que jamais conseguirá dela sair. Um novo componente dessa crise se manifesta, na situação atual, com a controvérsia ligada às alternativas dos Institutos Superiores de Educação e Escolas Normais Superiores introduzidas pela nova LDB. 


\section{Conclusão}

Pela trajetória traçada pode-se ver que, a partir da década de 1930, a pedagogia ocupou um espaço permanente na estrutura do ensino superior. Entretanto, com exceção do breve ensaio da Universidade do Distrito Federal, esse espaço limitou-se à formação profissional não se configurando como um espaço propriamente investigativo, o que resultou num ensino as mais das vezes precário e pouco consistente sob o aspecto da sua fundamentação teórico-científica. Assim, a área pedagógica foi objeto de um certo estigma, reforçado pelo baixo status social da profissão docente. Com o advento da pós-graduação, a área de educação tendeu a se firmar, assegurando o seu espaço acadêmico diante das outras áreas ao preço, porém, de elidir tanto a terminologia como a problemática própria da pedagogia.

Schmied-Kowarzik ressalta no prefácio do livro "Pedagogia dialética" que se tornou comum buscar nas ciências próximas questões e posições teóricas para aplicá-las a problemas pedagógicos “em vez de continuar a desenvolver a tradição teórica e científica própria, tantas vezes negada, confrontando-a com questões e exigências novas”, quando a pedagogia é "justamente uma das ciências práticas mais ricas em tradição (Schmied-Kowarzik, 1983, p.7).

Ao tratar da "pedagogia como ciência prática" mostra que "a relação entre teoria e prática é a mais fundamental da pedagogia”. Indica os campos em que essa relação se manifesta para considerar que à primeira vista ela parece bastante simples, resumindose na reciprocidade entre os dois pólos que a constituem, mas observa que se trata de uma relação complexa, sendo "preciso lembrar que, além da pedagogia, nenhuma outra das ciências 'burguesas' tradicionais ensinadas atualmente nas universidades conhece este problema da mediação entre teoria e prática”, como mostram os casos do direito, da teologia e da medicina. Em relação ao direito e à teologia não acontece o problema da mediação entre teoria e prática porque elas "não requerem nenhuma investigação da prática, podendo partir de proposições normativas ou de sentido, simplesmente desenvolvidas na prática de acordo com as normas e com habilidade técnica”. Também no caso da medicina não aparece o referido problema porque a ela basta "traduzir na prática de modo técnico-artesanal os conhecimentos que tem das doenças e do seu combate, sob a égide da finalidade determinada da cura" (Schmied-Kowarzik, 1983, p.11). E conclui:

"Caso a pedagogia perdesse de vista inteiramente a sua dialética constitutiva entre teoria e prática, ou aconteceria com ela o mesmo que ocorreu àciência política, outrora também uma ciência prática, que perdeu qualquer capacidade de influir na práxis política enquanto ciência do conhecimento histórico e sociológico ou ciência expositiva jurídica, ou então - o que é mais provável - se tornaria, como a medicina, uma ciência profissional pragmática do professor, mera transmissora de conhecimentos para o domínio das aptidões técnicas e artesanais da orientação do ensino, submetida a objetivos determinados politicamente.” (Schmied-Kowarzik, 1983, p.12).

Esse alerta resulta importante, pois é possível notar que o tratamento dado à questão pedagógica, desde o Decreto-Lei 1.190 de 1939 passando pelas Indicações de Valnir Chagas em 1975, até a nova LDB com os Institutos Superiores de Educação e as Escolas Normais Superiores, tendeu a reduzir a pedagogia a "uma ciência profissional pragmática do professor, mera transmissora de conhecimentos para o domínio das aptidões técnicas e artesanais da orientação do ensino".

Parece, então, que o caminho a percorrer começa pelo resgate da longa e rica tradição da pedagogia buscando explicitar, no conjunto de suas determinações, a relação íntima que mantém com a educação enquanto prática da qual se origina e à qual se destina. Para realizar esse itinerário supõe-se necessário retomar as principais concepções de educação de modo a sistematizar, a partir delas, os principais conceitos constitutivos da pedagogia. Com esse propósito a continuidade da investigação da qual se originou este trabalho deverá articular a abordagem histórica com a perspectiva teórica do problema em estudo. 
124 Dermeval Saviani

\section{Referências Bibliográficas}

BRASIL, CFE (1962). "Parecer n. 251/62”. Documenta, n. 11, p.59-65.

BRASIL, CFE (1969). “Parecer n. 252/69”. Documenta, n. 100, p.101-117.

BRASIL, CFE (1972). "Parecer n. 867/72”. Documenta, n. 140, p.339-341.

Brzezinski, I. (2002). Pedagogia, pedagogos e formação de professores. Campinas: Papirus. $4^{\mathrm{a}}$ edição.

Chagas, V. (1976). Formação do magistério: novo sistema. São Paulo: Atlas.

Cunha, L.A. (1986). A universidade temporã. Rio de Janeiro: Francisco Alves. $2^{\mathrm{a}}$ edição.

Fávero, M.L.A. (2000). Universidade e poder. Brasília: Plano. $2^{\mathrm{a}}$ edição.

Garcia, W.E. [Org.] (1980). Inovação educacional no Brasil: problemas e perspectivas. São Paulo: Cortez/Autores Associados.

Mendonça, A.W.P. (2002). Anísio Teixeira e a universidade da educação. Rio de Janeiro: EDUERJ.

Reis-Filho, C. (1995). A educação e a ilusão liberal: origens da escola pública paulista. Campinas: Autores Associados. $2^{\mathrm{a}}$ edição.

Schmied-Kowarzik, W. (1983). Pedagogia dialética: de Aristóteles a Paulo Freire. São Paulo: Brasiliense.

Silva, C.S.B. (2003). Curso de pedagogia no Brasil: história e identidade. Campinas: Autores Associados. $2^{\mathrm{a}}$ edição revista e ampliada.

Vidal, D.G. (2001). O exercício disciplinado do olhar: livros, leituras e práticas de formação docente no Instituto de Educação do Distrito Federal (1932-1937). Bragança Paulista: EDUSF.

Xavier, L.N. (1999). O Brasil como laboratório: educação e ciências sociais no projeto do Centro Brasileiro de Pesquisas Educacionais. Bragança Paulista: EDUSF.
Versão condensada do texto correspondente à conclusão da primeira etapa da pesquisa "O espaço acadêmico da pedagogia no Brasil: perspectiva histórica e teórica”, em desenvolvimento junto ao Departamento de Psicologia e Educação da FFCLRP, com apoio do CNPq. Uma versão ainda mais resumida foi apresentada no XXV Congresso da ISCHE (International Standing Conference for the History of Education), em São Paulo, julho de 2003. 